\title{
A Net for Catching Plankton near the Bottom.
}

By

\author{
F. S. Russell, D.S.C., B.A. \\ Assistant Naturalist at the Plymouth Laboratory.
}

With 2 Figures in the Text.

In the course of the researches on the vertical distribution of plankton it became evident that a net was needed for sampling the water-layers very close to the sea bottom. While the net had to be efficient in capturing the plankton animals present in those layers, it was necessary that the catches should not be vitiated by the presence of bottom-living organisms which had been stirred up from the sea floor by the net itself.

The necessity of using such a net has been strikingly demonstrated in the case of the post-larval stages of Pilchards and Sprats. It has happened repeatedly that the catches of these young fishes made by the ring-trawl are nearly ten times greater at night than in the daytime, even though the water-layers be sampled thoroughly down to a few metres above the bottom. Similar experiences have been noted at certain times also with Tomopteris helgolandica and Sayitta bipunctata. These observations point to the fact that the animals mentioned must have been living very close to the bottom in the daytime. In an attempt to capture these members of the planktion the net described below has been adopted. It has been shown in practice that it samples a layer about 7 inches above the bottom and 1 foot in thickness, capturing therefrom many plankton animals. Furthermore, the catches have been almost devoid of sand and gravel, or other bottom deposits, indicating that the capture of organisms stirred up from the bottom itself is probably very small.

The Net.

The net is made of "stramin," a Danish sacking made of threads of closely-spun hemp yarn, the meshes of which are merely interwoven and not knotted, with 15 to 16 strands to the inch. It has a rectangular mouth 4 feet in width and 1 foot in depth. It is 8 feet in length, and tapers to a circumference of 16 inches to take an ordinary tow-net bucket about 4 inches in diameter. The net is made in two main pieces, with two triangular gussets inset in front along the sides for a length of 3 feet 
6 inches. The seams of the net are roped, as is also the edge of the mouth. The sides of the mouth are supported by round poles just over 1 foot in length. The net is, in fact, built on the same principle as the Young fish trawl Type A net described and figured by Clark (Journ. Mar. Biol. Assoc., N.S., Vol. XII, No. 2, 1920, p. 163 and Fig. 1), except that the dimensions are different.

When fishing, the net is fixed to an Agassiz trawl frame (Fig. 1). Four short bridles from the stramin net are attached to the hind corners of the Agassiz shoes, care being taken to attach these bridles inside so that when the net is fishing they will not be chafed on the bottom. The two upright

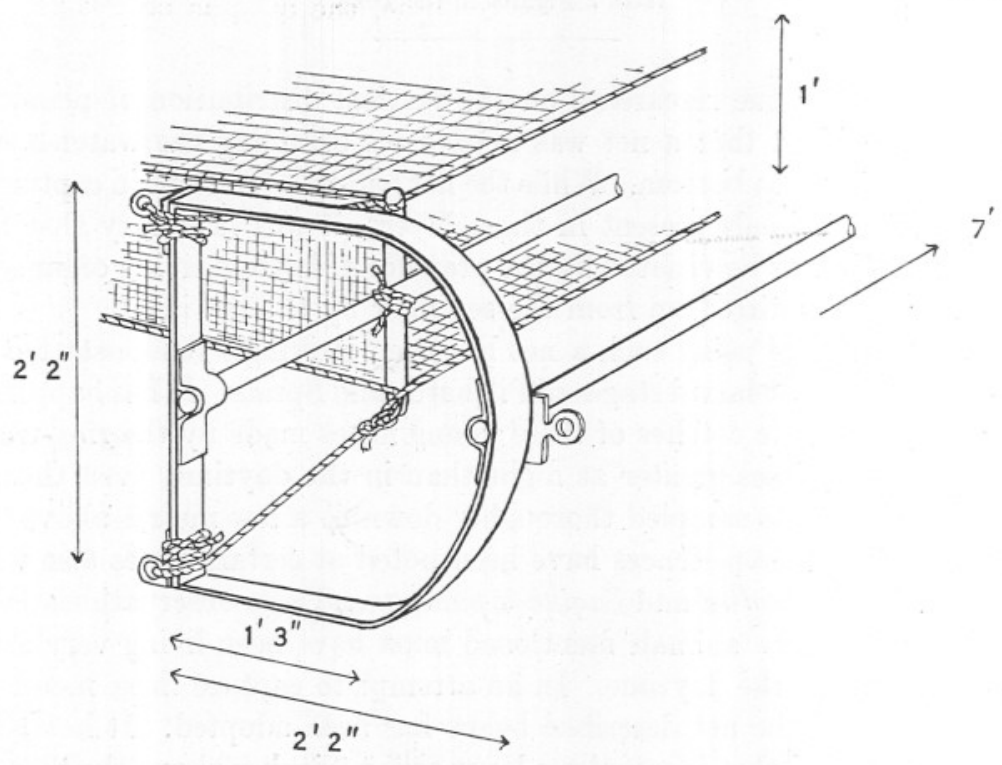

Text-Fig. 1.-Showing attachment of stramin net to Agassiz frame.

poles are then stopped to the rear horizontal bar of the Agassiz frame so as to keep the net central. The Agassiz trawl net itself is also fixed to the frame in the usual manner; the foot-ropes are, however, slacked off slightly so that, when fishing, they belly back behind the opening of the stramin net (Fig. 2).

The Agassiz frame in use is of the following dimensions: Height of shoe, 2 feet 2 inches; length of flat part of shoe, 1 foot 3 inches; total length of shoe, 2 feet 2 inches. The iron of which the shoes are made is $\frac{3}{16}$ of an inch in thickness and $2 \frac{1}{4}$ inches wide. The weight of each shoe is about $35 \mathrm{lbs}$. ; the weight of the whole frame, with shackles, being nearly 1 cwt. The two shoes are held together by a pair of horizontal bars $1 \frac{1}{4}$ inches in diameter and 7 feet in length. 
If the stramin net is fixed centrally on the rear bar of the Agassiz it will have a clearance of 7 inches from the sea bottom, the height of the net being 1 foot and that of the Agassiz shoe 2 feet 2 inches. There will also be a clearance of 1 foot 6 inches at either end between the stramin net and the shoes: thus any material stirred up from the bottom by the shoes will be swept past the mouth of the net. At the same time, by slackening off the foot-ropes, one can ensure that the bottom is only stirred up by them behind the mouth of the net.

The cod-end of the Agassiz trawl net itself need not be tied up, so that any large spiny animals entering the net may pass out again and not damage the stramin net; at the same time, the net has been fished on

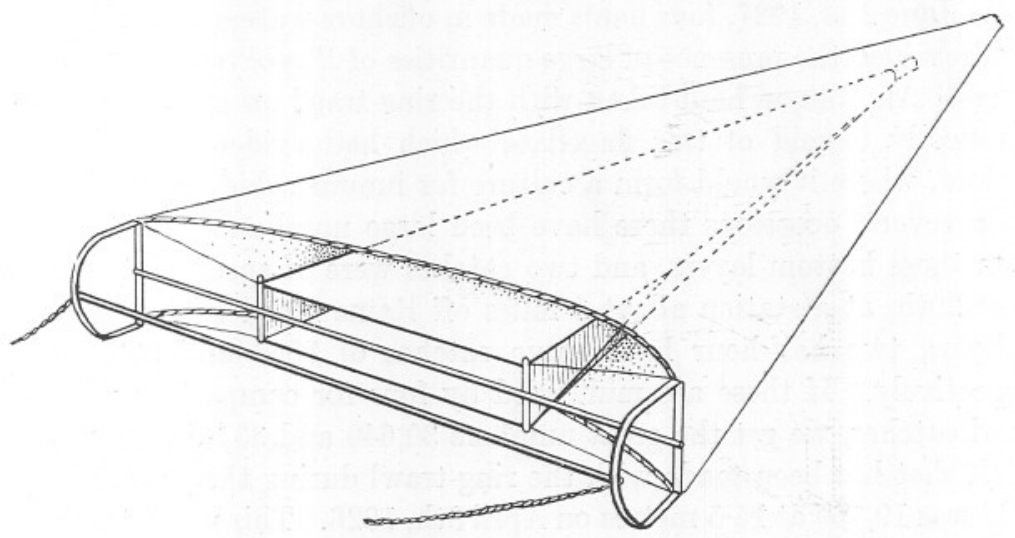

Text-Fig. 2.-Showing method of fishing.

several occasions with the cod-end tied up, thus effecting a dual purpose. The presence of the Agassiz trawl saves the stramin net from chafing on the sea floor.

The net has now been in operation for over fifty hauls, each of half an hour's duration, and in every case the catches have been successful. The presence of sand or gravel in the catches is rare, and then only in such small quantities as to give the idea that it was already in suspension, due to tidal action rather than to disturbance caused by the net.

The net is towed with the engines going very slow, if anything slightly faster than for the ring-trawl, in order to prevent the shoes digging too deep into a soft bottom.

The dimensions of the opening ( 1 foot $\times 4$ feet) give a fishing area similar to that of a metre tow-net, so that such a net can be adapted for the purpose. This area being almost exactly a quarter of that of the 2 -metre ring-trawl, the catches made by the two nets may at once be roughly compared. Seeing that there will be a greater chance of animals avoiding 
the narrow mouth of the small net and that, owing to the presence of the rear bar of the Agassiz frame, its fishing capacity is probably not improved, one is justified in regarding a catch multiplied by four as being a minimum estimate of a catch made by a ring-trawl, if it had been used instead.

A further advantage of this net is that it could probably as easily be used on a beam-trawl frame if an Agassiz frame was not available. Improvements could be made by the building of a special frame to do away with the bar which lies immediately in the mouth of the net.

While it is as yet too early to discuss the results obtained by the net, mention may be made of one or two catches of interest.

On June 2nd, 1927, four hauls made in offshore waters in the Plymouth area revealed the presence of large quantities of Phæocystis in the bottom layers. An oblique haul taken with the ring-trawl on the same day was practically devoid of this flagellate which had evidently sunk to the bottom, where it would form a culture for innumerable small organisms.

On several occasions there have been large numbers of Sagitta taken from these bottom layers, and two catches were of special interest. On June 29th, at a station about 3 miles off Rame Head in a depth of 20 fathoms, two half-hour hauls gave catches of 7660 and 8330 Sagitta respectively. If these are multiplied by four for comparison with ringtrawl catches, we get the great numbers 30,640 and 33,320 . The largest catch that has been made with the ring-trawl during the years 1925 and 1926 was 19,360 at 15.5 metres on April 9 th, 1926. This was a ten-minute haul, or, to compare it with the half-hour catch of the bottom stramin net, $19,360 \times 3=58,080$. These great catches made in June near the bottom may well explain the great diurnal variation in number of Sagitta in the upper layers mentioned in a further paper on page 87 of this Journal. (Journ. Mar. Biol. Assn., N.S., Vol. XV, No. 1, 1928, p. 81.)

As is to be expected, there are often many mysids in the catches, and Euphausiids are generally present in small numbers. On July 8th there was a large catch of 2210 mysids in a half-hour haul.

It is quite to be expected that in course of time many young stages of animals that have been rarely caught will appear in greater quantity in such collections. For instance, several young stages of the Squid up to a length of about $1_{4}^{1}$ inches have already been taken. Such a net should prove of great use for capturing in good condition many of the smaller bottom-haunting animals in very deep waters.

I am much indebted to Mr. E. Ford for his assistance in drawing the figures. 